This article is licensed under the Creative Commons Attribution-NonCommercial 4.0 International License (CC BY-NC) (http://www.karger.com/Services/OpenAccessLicense). Usage and distribution for commercial purposes requires written permission.

\title{
Sequential Bilateral Vertebral Artery Dissections with Prompt Resolution of Initial Insult
}

\author{
Sarkis Morales Vidal Carlos Lara Ari Gordin \\ Department of Neurology, Loyola University Medical Center, Maguire Center, \\ Maywood, IL, USA
}

\section{Keywords}

Ischemic stroke · Dissection - Vasculopathy · Vertebral artery

\begin{abstract}
Vertebral arterial dissection is a known cause of stroke in young adults. There has been a multitude of cases of bilateral vertebral dissections, including progression from one vertebral artery to another. This case reports the curious sequential nature of the healing of a previously dissected vertebral artery with subsequent dissection of the collateral vertebral artery. Followup neuroimaging evaluation performed several months later showed healed bilateral vertebral artery. The potential trigger was neck cracking.

(C) 2020 The Author(s)

Published by S. Karger AG, Basel
\end{abstract}

\section{Case Presentation}

A 32-year-old right handed man presented to the emergency room with persistent dizziness and neck pain for the past 3 days. He was discharged home 1 month prior after being diagnosed with a cerebellar infarction secondary to a spontaneous right vertebral artery dissection (Fig. 1, 2, 3). The clinical presentation of the first event was headaches associated with 


\section{Case Reports in Neurology}

Case Rep Neurol 2020;12:189-198

DOI: $10.1159 / 000506766$

Morales Vidal et al.: Sequent

Resolution of Initial Insult

dizziness and right beating nonpersistent horizontal nystagmus. He reported to occasionally cracking his neck during his initial admission but reported not cracking his neck during his second admission. His family history was pertinent for a spontaneous left cervical carotid dissection in his mother at the age of 41 years. He had no history of illicit drug use, alcohol abuse, or cigarette smoking. General examination was normal. No abnormal body habitus. No blue sclera. No skin abnormalities like cutaneous xanthomas or other abnormalities suggestive of connective tissue disease were observed. The neurologic examination during his second admission was normal and symptoms of neck pain and dizziness resolved within $24 \mathrm{~h}$. Neuroimaging studies performed during his second admission included MRI of the brain and MRA of the head/neck initially and then followed by CTA of the head and neck. MRI brain during his second admission showed no evidence of recurrent cerebral or cerebellar infarction; however, MRA of the head showed an intracranial vertebral artery narrowing most consistent with arterial dissection on the left and recanalization of the previously seen right vertebral dissection during his prior admission (Fig. 4, 5). Additional investigations including lipid profile hemoglobin $\mathrm{A} 1 \mathrm{C}$, and other routine testing were within reference laboratory values. He had further testing, including alpha-1 antitrypsin levels, CTA of the renal arteries, genetic testing for COAL3A4 (vascular Ehlers-Danlos), and homocysteine levels that were all unremarkable. Antinuclear antibody screen test was negative (test performed using HEP 2 cells and screened at 1:40 dilution); however, anti-RNP (ribonucleoprotein) antibodies were 38 units (normal reference range: $<20$ units). Rheumatology revaluated the patient and their impression was that the slightly elevated anti-RNP antibodies were nondiagnostic and that the patient did not meet all criteria for the diagnosis of mixed connective tissue disease. The patient was initially started on aspirin and clopidogrel; however, he was unable to tolerate clopidogrel due to an allergic reaction, hence he was continued on aspirin monotherapy. In addition, the patient was also started on statin therapy. He was discharged home asymptomatic and with a normal neurologic examination. Follow-up neuroimaging evaluation performed several months later showed resolution of left vertebral dissection. Statin therapy was discontinued and he was maintained on low-dose aspirin therapy.

\section{Discussion}

Cervicocephalic arterial dissection is a known cause of stroke in young adults. The most commonly identifiable cause is trauma; however, the underlying etiology is frequently unclear. There are many cases diagnosed as spontaneous arterial dissections with underlying predisposing risk factors. Observational studies have recognized an association between several types of minor trauma and cervicocephalic arterial dissections [1]. Neck cracking has been associated with vertebral artery dissection; however, causality is difficult to establish [2]. Weather neck cracking played a role as the underlying cause in this patient's recurrent multivessel vertebral artery dissections is not completely clear. Anti-RNP antibodies were of questionable significance. Thus far, there are reported cases of cervicocephalic vertebral dissection associated with mixed connective tissue disease. Nonetheless, Ohki et al. [3] reported a case of an intracranial dissecting aneurysm involving the posterior cerebral artery. The decision to start him on statin therapy was based on indirect evidence of vessel remodeling [4]. 
Bilateral vertebral artery dissection has been reported in multiple scenarios including subarachnoid hemorrhage, acute disseminated encephalomyelitis (ADEM), sports related, in association with osteogenesis imperfecta, as the initial presentation of Cushing's syndrome, trampoline use, cervical spine manipulation, postpartum period, eclampsia and HELLP, labor and delivery, essential thrombocytopenia, dynamic arterial compression, blunt trauma, connective tissue aberrations, Hirschsprung's disease, syphilis, fibromuscular dysplasia, chiropractic manipulation, facial massage, neck cracking, roller coaster ride, and various gene mutations. Table 1 and Table 2 provide a summary of selected reported cases of bilateral vertebral dissections in association with particular diseases [5-41].

This case should encourage new research to better understand the process of healing of a dissected vertebral artery. Our case is unique since our patient exhibited successive spontaneous intracranial vertebral dissections with evidence of prompt (within 1 month) resolution of the initially dissected vessel. The intriguing mechanism of these events could be related to an underlying connective tissue disease (positive family history) in association with minor trauma (neck cracking).

\section{Statement of Ethics}

The authors confirm obtaining written consent from the patient for publication of the manuscript.

\section{Disclosure Statement}

The authors declare that the research was conducted in the absence of any commercial or financial relationships that could be construed as a potential conflict of interest.

\section{Funding Sources}

The authors received no funding for the publication of the manuscript.

\section{Author Contributions}

S.M., A.G., and C.L. contributed to the manuscript development, rationale, manuscript images, and patient management.

\section{References}

1 Biller J, Sacco RL, Albuquerque FC, Demaerschalk BM, Fayad P, Long PH, et al.; American Heart Association Stroke Council. Cervical arterial dissections and association with cervical manipulative therapy: a statement for healthcare professionals from the american heart association/american stroke association. Stroke. 2014 Oct;45(10):3155-74. 
2 Fujii M, Ohgushi M, Chin T. Brain infarction due to vertebral artery dissection caused by a bone protrusion from the condylar fossa in a juvenile case. Br J Neurosurg. 2018 Feb:1-3.

3 Ohki M, Nakajima M, Sato K, Kondo R, Saito S, Nakai O, et al. [A case of dissecting aneurysm associated with mixed connective tissue disease]. No To Shinkei. 1994 Sep;46(9):855-8.

4 Suzuki M, Saito M, Nagai T, Saeki H, Kazatani Y. Prevention of positive coronary artery remodeling with statin therapy in patients with coronary artery diseases. Angiology. 2006 May-Jun;57(3):259-65.

5 Zhao WY, Zhao KJ, Huang QH, Xu Y, Hong B, Liu JM. Single-stage endovascular treatment of subarachnoid hemorrhage related to bilateral vertebral artery dissecting aneurysms. Interv Neuroradiol. 2016 Apr;22(2):138-42.

6 Turowski B, Hanggi D, Siebler M. Intracranial bilateral vertebral artery dissection during anticoagulation after cerebral venous and sinus thrombosis (CSVT). Acta Neurochir (Wien). 2007 Aug;149(8):793-7.

7 Chang CM, Ng HK, Leung SY, Fong KY, Yu YL. Fatal bilateral vertebral artery dissection in a patient with cystic medial necrosis. Clin Neurol Neurosurg. 1991;93(4):309-11.

8 Shinoda S, Murata H, Waga S, Kojima T. Bilateral spontaneous dissection of the posteroinferior cerebellar arteries: case report. Neurosurgery. 1998 Aug;43(2):357-9.

9 Raza HK, Jing J, Chen H, Zhu J, Zhang Z, Chansysouphanthong T, et al. A Rare Case of Bilateral Vertebral Artery Dissection Associated with Essential Thrombocythemia. J Neurol Surg A Cent Eur Neurosurg. 2020 Jan;81(1):75-9.

10 Verdure P, Lefaucheur R, Guegan-Massardier E, Triquenot-Bagan A, Gerardin E, Maltête D. Bilateral vertebral artery dissection and essential thrombocythemia with JAK2 mutation. Rev Neurol (Paris). 2012 Jun;168(6-7):543-4.

11 Mawet J, Debette S, Bousser MG, Ducros A. The Link Between Migraine, Reversible Cerebral Vasoconstriction Syndrome and Cervical Artery Dissection. Headache. 2016 Apr;56(4):645-56.

12 Ohshima T, Miyachi S, Isaji T, Matsuo N, Kawaguchi R, Takayasu M. Bilateral Vertebral Artery Dissection and Unilateral Carotid Artery Dissection in Case of Ehlers-Danlos Syndrome Type IV. World Neurosurg. 2019 Jan;121:83-7.

13 Lill CM, Günther-Kunkel K, Hoch H, Paul F, Grond-Ginsbach C, Hausser I, et al. Bilateral vertebral artery dissection, agenesis of both ICAs, and connective tissue aberrations. Neurology. 2013 Apr;80(15):1442-3.

14 Najem K, Margolin E, Krishnan P. Syphilitic Perineuritis with Preserved Visual Function. In 42nd Annual Meeting. 2016;22.

15 Pan X, Ma A, Wang K, Nie S, Wu M. Vertebral artery dissection associated with viral meningitis. BMC Neurol. 2012 Aug;12(1):79.

16 Stirn SL, Freilinger C, Roeben B, Tünnerhoff J, Berg D, Freilinger T. Bilateral vertebral artery dissection in the setting of ADEM. J Neurol Sci. 2016 Jun;365:212-3.

17 Ilie I, Vouillarmet J, Decaussin-Petrucci M, Jeannin-Mayer S, Lifante JC, Thivolet C, et al. Bilateral vertebral artery dissection revealing Cushing's syndrome. Ann Endocrinol (Paris). 2019 Feb;80(1):67-9.

18 Mitchell LA, Santarelli JG, Singh IP, Do HM. Reversible cerebral vasoconstriction syndrome and bilateral vertebral artery dissection presenting in a patient after cesarean section. J Neurointerv Surg. 2014 Jan;6(1):e5.

19 Mass SB, Cardonick E, Haas S, Gopalani S, Leuzzi RA. Bilateral vertebral artery dissection causing a cerebrovascular accident in pregnancy. A case report. J Reprod Med. 1999 Oct;44(10):887-90.

20 Simon EL, Griffin G, Bosman E. Bilateral carotid and vertebral artery dissection: a life-threatening cause of postpartum headache. Am J Emerg Med. 2015 Apr;33(4):600.e1-3.

21 Borelli P, Baldacci F, Vergallo A, Del Dotto P, Lucetti C, Nuti A, et al. Bilateral thalamic infarct caused by spontaneous vertebral artery dissection in pre-eclampsia with HELLP syndrome: a previously unreported association. J Stroke Cerebrovasc Dis. 2012 Nov;21(8):914.e9-10.

22 Ma Y, Li M, Zhang H, Ling F. A 10-year follow-up of extracranial-intracranial bypass for the treatment of bilateral giant internal carotid artery aneurysms in a patient with fibromuscular dysplasia: case report. Acta Neurochir (Wien). 2010 Dec;152(12):2191-5.

23 Hotait M, Sawaya R. Spontaneous bilateral vertebral artery dissection secondary to PAI-1, MTHFR C677T and ACE gene mutations in a young man. Cerebrovasc Dis. 2013;35(2):182-3.

24 Kato Y, Nagoya H, Abe T, Hayashi T, Yasuda M, Uchino A, et al. Progressive Bilateral Vertebral Artery Dissection in a Case of Osteogenesis Imperfecta. J Stroke Cerebrovasc Dis. 2017 Mar;26(3):e43-6.

25 García-Moncó JC, Fernández Cantón G, Gómez Beldarrain M. Bilateral vertebral artery dissection in a patient with afibrinogenemia. Stroke. 1996 Dec;27(12):2325-7.

26 Sato K, Sasaki R, Ohta Y, Takemoto M, Hishikawa N, Yamashita T, et al. A Unique Recurrent Stroke Case due to Bilateral Vertebral Artery Dissection with Familial Hirschsprung Disease. J Stroke Cerebrovasc Dis. 2019 Aug;28(8):e113-5. 
27 Ke JQ, Yin B, Fu FW, Shao SM, Lin Y, Dong QQ, et al. A Case Report of Locked-in Syndrome Due to Bilateral Vertebral Artery Dissection After Cervical Spine Manipulation Treated by Arterial Embolectomy. Medicine (Baltimore). 2016 Feb;95(5):e2693.

28 Gantwerker BR, Baaj AA, Maughan PH, McDougall CG, White WL. Vertebral artery injury during cervical discectomy and fusion in a patient with bilateral anomalous arteries in the disc space: case report. Neurosurgery. 2010 Sep;67(3):E874-5.

29 Manaouil C, Graser M, Delcour J, Le Gars D, Gontier MF, Loriau J, et al. Postoperative bilateral vertebral artery dissection: a case report. J Clin Forensic Med. 2003 Jun;10(2):81-4.

30 Mas Rodriguez MF, Berrios RA, Ramos E. Spontaneous Bilateral Vertebral Artery Dissection During a Basketball Game: A Case Report. Sports Health. 2016 Jan-Feb;8(1):53-6.

31 Frankowska E, Brzozowski K, Staszewski J, Kolmaga N, Stępień A, Bogusławska-Walecka R. Combined thrombolysis in posterior circulation stroke caused by bilateral vertebral artery dissection in squash player. Neurol Neurochir Pol. 2014;48(4):299-304.

32 Leys D, Lesoin F, Pruvo JP, Gozet G, Jomin M, Petit H. Bilateral spontaneous dissection of extracranial vertebral arteries. J Neurol. 1987 May;234(4):237-40.

33 Karnik R, Rothmund T, Bonner G, Valentin A, Reuther G. Inline skating as a possible cause of consecutive bilateral vertebral artery dissection. Acta Neurol Scand. 2000 Jan;101(1):70-1.

34 Ozkan Arat Y, Volpi J, Arat A, Klucznik R, Diaz O. Bilateral internal carotid artery and vertebral artery dissections with retinal artery occlusion after a roller coaster ride - case report and a review. Ulus Travma Acil Cerrahi Derg. 2011 Jan;17(1):75-8.

35 Rollins N, Braga B, Hogge A, Beavers S, Dowling M. Dynamic Arterial Compression in Pediatric Vertebral Arterial Dissection. Stroke. 2017 Apr;48(4):1070-3.

36 Ariyada K, Shibahashi K, Hoda H, Watanabe S, Nishida M, Hanakawa K, et al. Bilateral Internal Carotid and Left Vertebral Artery Dissection after Blunt Trauma: A Case Report and Literature Review. Neurol Med Chir (Tokyo). 2019 Apr;59(4):154-61.

37 Chakrapani AL, Zink W, Zimmerman R, Riina H, Benitez R. Bilateral carotid and bilateral vertebral artery dissection following facial massage. Angiology. 2008 Dec;59(6):761-4.

38 Iwanami H, Odaka M, Hirata K. [Bilateral cerebellar infarction caused by intracranial dissection of the vertebral artery after long periods of "Shiatsu"]. Brain Nerve. 2007 Feb;59(2):169-71. Japanese.

39 Kuitwaard K, Flach HZ, van Kooten F. [Bilateral vertebral artery dissection during chiropractic treatment]. Ned Tijdschr Geneeskd. 2008 Nov;152(45):2464-9.

40 Dickinson LD, Tuite GF, Colon GP, Papadopoulos SM. Vertebral artery dissection related to basilar impression: case report. Neurosurgery. 1995 Apr;36(4):835-8.

41 Thomas LC, Makaroff AP, Oldmeadow C, Attia JR, Levi CR. Seasonal variation in cervical artery dissection in the Hunter New England region, New South Wales, Australia: A retrospective cohort study. Musculoskelet Sci Pract. 2017 Feb;27:106-11. 


\section{Case Reports in Neurology}

\section{Case Rep Neurol 2020;12:189-198}

DOI: $10.1159 / 000506766$

(C) 2020 The Author(s). Published by S. Karger AG, Basel www.karger.com/crn

Morales Vidal et al:: Sequential Bilateral Vertebral Artery Dissections with Prompt

Resolution of Initial Insult

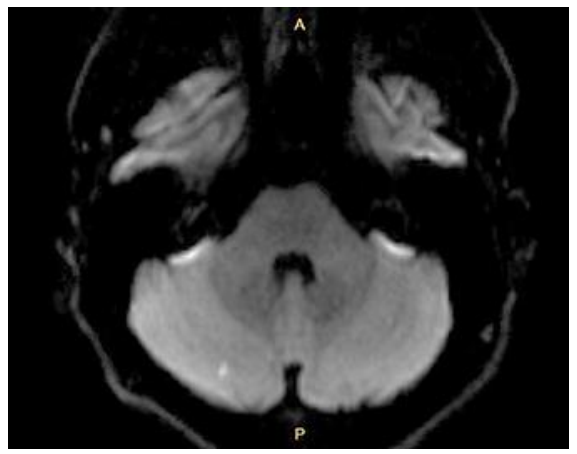

Fig. 1. Axial diffusion-weighted image showing a punctate region of an acute right inferior cerebellar infarction.

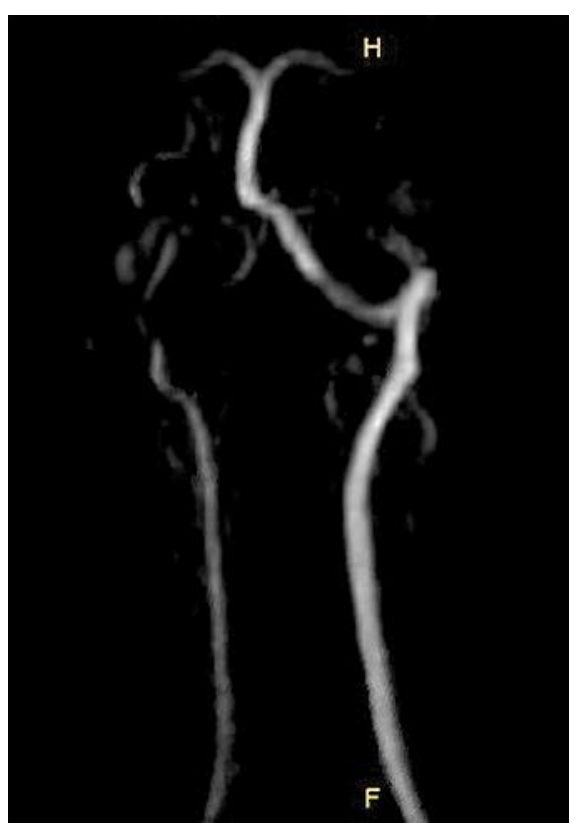

Fig. 2. Reconstructed MRA showing evidence of decreased flow in the distal right vertebral artery. 


\section{Case Reports in Neurology}

\section{Case Rep Neurol 2020;12:189-198}

DOI: $10.1159 / 000506766$

(C) 2020 The Author(s). Published by S. Karger AG, Basel www.karger.com/crn

Morales Vidal et al.: Sequential Bilateral Vertebral Artery Dissections with Prompt

Resolution of Initial Insult

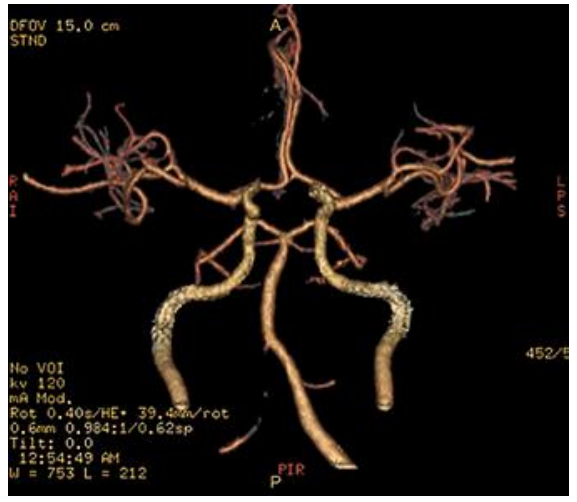

Fig. 3. Reconstructed CRA showing evidence of decreased flow in the distal right vertebral artery.

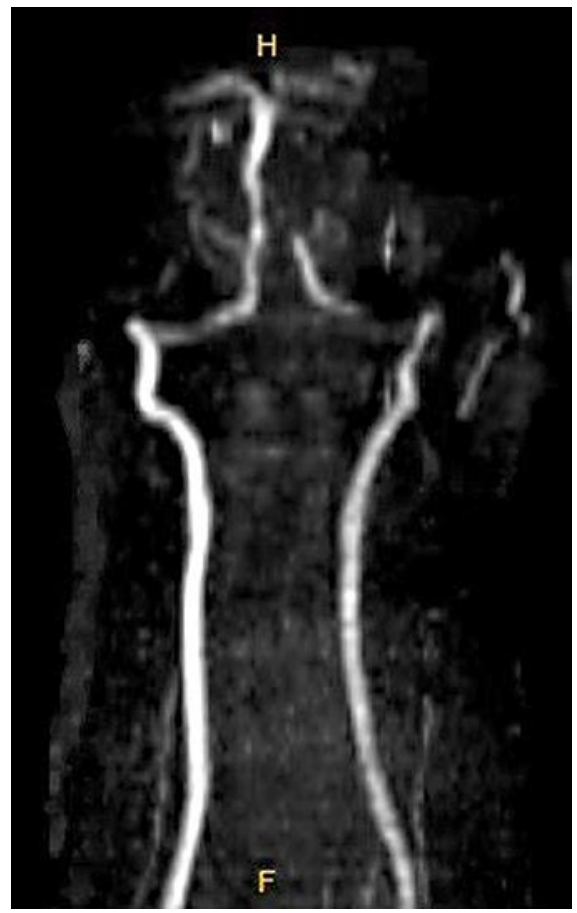

Fig. 4. Reconstructed MRA during the second admission showing evidence of decreased flow in the distal left vertebral artery with resolution of the previously seen right vertebral artery. 


\section{Case Reports in Neurology}

www.karger.com/crn

Morales Vidal et al:: Sequential Bilateral Vertebral Artery Dissections with Prompt

Resolution of Initial Insult

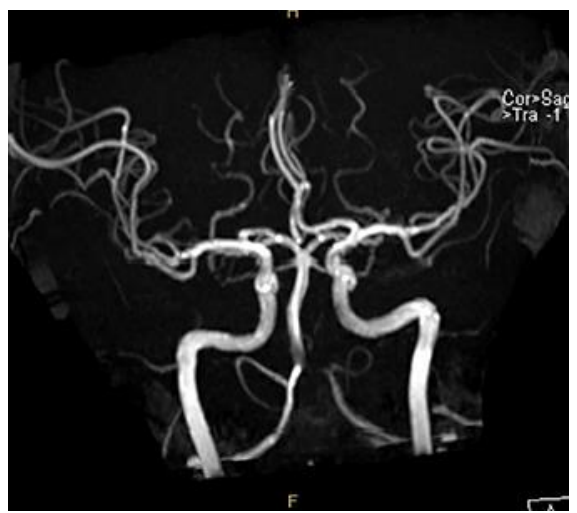

Fig. 5. Intracranial view of reconstructed MRA during the second admission showing evidence of decreased flow in the distal left vertebral artery with resolution of the previously seen right vertebral artery. 
Table 1. Cerebrovascular diseases with reported associated bilateral dissections of vertebral arteries

Cerebrovascular and Related Disorders

SAH Subarachnoid hemorrhage with bilateral intracranial vertebral artery dissecting aneurysms [5]

Cerebral sinus venous thrombosis Intracranial bilateral vertebral artery dissection during anticoagulation after cerebral venous and sinus thrombosis (CSVT) [6]

Cystic medial necrosis $\quad$ Fatal bilateral vertebral artery dissection in a patient with cystic medial necrosis [7]

Intracranial aneurysm Bilateral spontaneous dissection of the posteroinferior cerebellar arteries [8]

Essential thrombocythemia $\quad$ A rare case of bilateral vertebral artery dissection associated with essential thrombocythemia [9] Bilateral vertebral artery dissection and essential thrombocythemia with JAK2 mutation [10]

Reversible cerebral

vasoconstriction

The link between migraine, reversible cerebral vasoconstriction syndrome and cervical artery dissection [11]

Connective Tissue Disease

Connective tissue disease

Bilateral vertebral artery dissection and unilateral carotid artery dissection in case of Ehlers-Danlos syndrome type IV [12]

Bilateral vertebral artery dissection, agenesis of both ICAs, and connective tissue aberrations [13]

Infectious

Syphilis

Bilateral vertebral artery and internal carotid artery dissecting aneurysms due to syphilis [14]

Viral meningitis

Vertebral artery dissection associated with viral meningitis [15]

Autoimmune

ADEM

Bilateral vertebral artery dissection in the setting of ADEM [16]

Metabolic/Endocrine/Toxic

Cushing's syndrome

Bilateral vertebral artery dissection revealing Cushing's syndrome [17]

Pregnancy Related

Cesarean section

Reversible cerebral vasoconstriction syndrome and bilateral vertebral artery dissection presenting in a patient after cesarean section [18]

Pregnancy

Bilateral vertebral artery dissection causing a cerebrovascular accident in pregnancy [19]

Postpartum period

Bilateral carotid and vertebral artery dissection: a life-threatening cause of postpartum headache [20]

Preeclampsia and HEELP

Bilateral thalamic infarct caused by spontaneous vertebral artery dissection in pre-eclampsia with HELLP syndrome [21]

Genetic and Congenital Disorders

Single-nucleotide polymorphism of PHACTR1

Spontaneous bilateral cervical internal carotid and vertebral artery dissection in a Japanese patient without collagen vascular disease with special reference to single-nucleotide polymorphisms [22]

PAI-1, MTHFR C677T, and ACE Spontaneous bilateral vertebral artery dissection secondary to PAI-1, MTHFR C677T, and ACE gene mutations in a young man [23]

Osteogenesis imperfecta $\quad$ Progressive bilateral vertebral artery dissection in a case of osteogenesis imperfecta [24]

Afibrinogenemia $\quad$ Bilateral vertebral artery dissection in a patient with afibrinogenemia [25]

Hirschsprung's disease Bilateral vertebral artery dissection with familial Hirschsprung's disease [26]

Fibromuscular dysplasia

Follow-up of intracranial aneurysms in patients with fibromuscular dysplasia [22] 
Morales Vidal et al.: Sequential Bilateral Vertebral Artery Dissections with Prompt Resolution of Initial Insult

Table 2. Cerebrovascular diseases with reported associated bilateral dissections of vertebral arteries (continued)

Trauma/Minor Trauma

Cervical spine manipulation

Locked-in syndrome due to bilateral vertebral artery dissection after cervical spine manipulation [27]

Vertebral artery injury during cervical discectomy and fusion in a patient with bilateral anomalous arteries in the disc space [28]

Postoperative bilateral vertebral artery dissection (cervical discectomy) [29]

\section{Neck cracking}

Patient with only associated trauma with recent self neck cracking [2]

Sports

Spontaneous bilateral vertebral artery dissection during a basketball game [30]

Combined thrombolysis in posterior circulation stroke caused by bilateral vertebral artery dissection in a squash player [31]

Bilateral spontaneous dissection of extracranial vertebral arteries (tennis) [32]

\begin{tabular}{ll}
\hline Inline skating & Inline skating as a possible cause of consecutive bilateral vertebral artery dissection [33] \\
\hline Roller coaster ride & $\begin{array}{l}\text { Bilateral internal carotid artery and vertebral artery dissections with retinal artery occlusion after a roller } \\
\text { coaster ride [34] }\end{array}$ \\
\hline Dynamic arterial compression & Dynamic arterial compression in pediatric vertebral arterial dissection [35] \\
\hline Blunt trauma & Bilateral internal carotid and left vertebral artery dissection after blunt trauma [36] \\
\hline Facial massage & $\begin{array}{l}\text { Bilateral carotid and bilateral vertebral artery dissection following facial massage [37] } \\
\text { Bilateral cerebellar infarction caused by intracranial dissection of the vertebral artery after long periods } \\
\text { of Shiatsu [38] }\end{array}$ \\
\hline Chiropractic manipulation & Bilateral vertebral artery dissection during chiropractic treatment [39] \\
\hline Cervical traction & Vertebral artery dissection related to basilar impression: case report [40] \\
\hline Temperature related & $\begin{array}{l}\text { Seasonal variation in cervical artery dissection in the Hunter New England region, New South Wales, Aus- } \\
\text { tralia: a retrospective cohort study [41] }\end{array}$
\end{tabular}

